\section{DRUGS AND SYNAPSES}

\section{The Pharmacology of Synapses}

By J. W. Phillis. (International Series of Monographs in Pure and Applied Biology. Division: Zoology, Vol. 43.) Pp. xi +358 . (Pergamon Press: London and New York, 1970.) $120 s ; \$ 16$.

OuR understanding of signalling processes across synaptic junctions in the nervous system has shown exciting progress in the past decade and it is discoveries in this period which the book describes. The author provides a factual and com. prehensive catalogue of what is now known of transmission at a wide range of synapses, but the order in which the material is presented is not ideal, with initial chapters on important general characteristics of possible transmitters at all sites. This is followed by chapters on transmission in the poripheral and central nervous systems of mammals and, following this, there is an account of invertebrate and molluscan synapses. This arrangement requires the reader to make frequent back references to obtain relevant metabolic and morphological information.

As a review this book is a notable success and the bibliography is excellent. Where the book fails and frustrates is in not providing interpretations or possible explanations of the frequently controversial information. There are numerous examples of this, for instance, when describing presynaptic transmitter actions, apparently contradictory experiments are quoted without comment or an attempt to equate the anomalies. This lack of critical approach has detracted particularly from the author's assessment of the status of possible transmitters at various sites. 'The criteria which should now be satisfied by a substance before it can be classed as a transmitter have been listed but have been couched in ambiguous terms and the author does not state which, if any, are essential. This indecision has allowed the author to make strong assertions as to the identity of the transmitters at many sites, including the lateral geniculate nucleus, mitral cells and cerebral cortex, although many important eriteria for each example have yet to be demonstrated. As the author himself points out, there are good reasons why extreme caution must be exercised in the identification of a neurotransmitter.

Many of the chapters lay great emphasis on the iontophoretic application of drugs to single neurones and, although some of the difficulties inherent in this technique are mentioned, the unpredictable quantities of many substances ejected is not remarked on. This may explain some of the divergent results which the author has attributed to anaesthetic effects or even to fluctuations in environmental conditions. Other important techniques have often been dealt with in a cursory fashion. Notable gaps occur in the uncritical description of in vitro studies and in describing the variety of information available on the evoked release of potential neurotransmitters.

Although the book disappoints in its unbalanecd roporting and unimaginative interpretation, there is no doubt that it forms a valuable source of information and provides a most comprehensive and much needed review of a complex and important subject. J. F. Mrtohell

\section{PEROXIDE REACTIONS}

The Determination of Organic Peroxides

By R. M. Johnson and I. W. Siddiqi. (Monographs in Organic Functional Group Analysis, Vol. 4.) Pp. ix + 119. (Pergamon Press: Oxford, London and New York, 1970.) $50 s ; \$ 6.75$.

AErobIC oxygen reacts with most types of organic compound to give organic peroxides in low eoncentration. Their structures and properties are almost as diverse as those of the organic monoxy compounds, and a wide variety of methods have been used in their analysis. This book serves as a guide to the most suitable procedure.

After an introductory chapter on the occurrence of organic peroxides, the various types are classified and their reactivities are related to their structures. This is oversimplified: there are some ten different mechanisms by which peroxides can react, and a compound which is unreactive by one mechanism may be very reactive by another.

The various types of chemical and physical analytical mothods (for example, iodometric, colorimetric, polarographic and chromatographic) are then discussed. Detailed procedures are quoted for the recommended methods, and examples of their applications are tabulated together with data such as half-wave potentials, $R_{f}$ values, and retention times. This is a useful, thorough, and critical compilation, and the best source of reference which is available in this field.

There are some shortcomings in nomenclature. Names such as succinic acid peroxide, phthalyl peroxide, and diisopropyl hydroperoxide are not very informative, even if they were used by the original authors. A number of half-truths also occur, which should not be taken at their face value. For example (p. 9), it is stated that "peresters are formed when alcohols react with peracids"; this may be possible in principle, but such a reaction has never been established.

These are minor points, however, and do little to detract from the value of a very useful review.

\section{A. G. Davies}

\section{DOWN'S SYNDROME}

\section{Measurement of the Facies}

A Study in Down's Syndrome. By Michael Joseph and Carol Dawbarn. (SIMP Research Monograph, No. 3.) Pp. xii +114 . (Spastics International Medical Publications in association with Heinemann (Medical): London, 1970.) $50 s ; \$ 7.50$.

Dr J. Langdon H. Down, in a paper published in tho London Hospital Reports for 1866 and entitled "Observations on the Ethnic Classification of Idiots", wrote that a very large number of congenital idiots are typical Mongols; so marked is this that, when placed side by side, it is difficult to believe that the specimens compared are not children of the same parents. Down further wrote that the face is flat and broad, and destitute of prominence; the cheeks are rounded and extended laterally; the eyes are obliquely placed and the internal canthi more than normally distant from one another; the palpebral fissure is narrow, the nose is small.

This classic description of the Mongol child was based on careful clinical observations, but clinical impressions may be inaccurate or misleading and require confirmation by methods involving exact measurements. The research monograph by Joseph and Dawbarn describes an original approach based on painstaking measuremonts of the face, eyes, nose, mouth and ears, and will prove invaluable to paediatricians and others who may be called upon to diagnose Down's syndrome; furthermore, the techniques can be used to define more accurately other disorders associated with an abnormal facial appearance.

The authors review the attempts from Aristotle (383 to $322 \mathrm{BC}$ ) through Albertus Magnus (AD 1192 to 1280), Leonardo da Vinci (1452 to 1519) and Peter Camper (1722 to 1789) to Topinard (1830 to 1911) to moasure the human face. These anthropologists and others were interested chiefly in bony landmarks, but the methods devised by Joseph and Dawbarn also take account of tho distribution of the soft tissue of the face.

Twenty infants within six months of birth in whom the diagnosis of Down's syndrome had boen confirmed cytogenetically were studied in detail, together with twenty 